Society for the Anthropology of Work • Essential Labor

\title{
Balancing Support: Essential Work for Homeless People during COVID-19
}

Johannes Lenhard

Published on: Jun 17, 2020

DOI: $10.21428 / 1 \mathrm{~d} 6$ be30e.9767d928

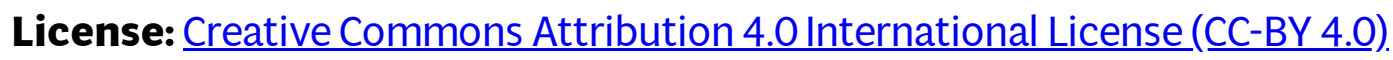


An official letter distributed in early April to all residents of the Hostel, ${ }^{1}$ a homeless emergency shelter in the United Kingdom, stated that everyone would be allowed thirty minutes outside each day. Multiple outings were explicitly forbidden. Ben, one of the residents who has been living at the Hostel much longer than the intended twentyeight days, explains to me several weeks later what was going on: "With these rules, they didn't know themselves. They didn't know what would work and what was necessary. It was all trial and error in the beginning, right? Thirty minutes: it takes me longer to go the pharmacy to pick up my prescription every week." The time limit was eventually changed after it became obvious that residents like Ben wouldn't be able to run their essential errands. The time outside was increased to two hours in no more than two blocks.

This first phase, after the stay-at-home orders were issued by the government, was one of adjusting, of trial and error. It wasn't clear what the rules were supposed to be at the Hostel. State guidance was opaque, and management had to act quickly. In recent weeks, I have been following the coping strategies of staff and residents alike as a researcher and volunteer at the Hostel. What I have observed is a kind of essential labor that consists in a tenuous balance between care and support, two concepts that have proved surprisingly at odds with one another in the time of COVID-19.

\section{Care and/or Support}

Paul, the Hostel's manager, told me about this form of frontline work that he and other staff members were performing. He made an important distinction:

We don't provide care; we provide support. If people need care, our job would be to liaise with social services, in particular, to get someone the care they need-or get them in the right kind of accommodation. ${ }^{2}$

This distinction also ran through the titles of staff at the hostel: they are support workers (or "key" workers), not care workers. Support enables people to find care for their mental or physical health or their substance use issue, but does not provision care itself. Rather, care is provided by mental health workers and nurses, by psychologists and psychiatrists who are experts on addiction as well as by doctors working in hospitals, as general practitioners, or in other specific institutions. Paul explains: 
Care in this country is regulated. It is quite different. It would be personal carehygiene, changing clothes-what happens in care homes or what care workers are providing. . . . Support is what the Hostel is doing: what do people need, what has led them to the point where they are now at, what do they need to do to move forward? We help the person work out how they can move on.

External providers of this more specialized, personal, and medicalized kind of care were not easily accessible when the stay-at-home orders were first put in place; many offices had to be shut temporarily in order to recalibrate to the new rules. As a consequence, the Hostel became the only place where residents could access any kind of help: support and urgent care alike. How did the staff, now frontline workers in two senses, manage this balance?

\section{Small Adjustments}

The transition to stay-at home was difficult, and made worse by sparse government guidance. At first, Hostel staff overcompensated, as with the thirty-minute limit on outings. Though the new rules were widely published and circulated among residents, they were also difficult to enforce because, as a matter of residents' well-being, breaches couldn't have strict consequences. What staff learned from the quick start was that they would have to work together with residents to figure out what was viable.

One area of collaboration concerned the seemingly mundane, but highly important question of television usage. Before the pandemic, all residents were supposed to leave their rooms between 9:30am and 4pm every day. The TV in the common area was not supposed to be on before $4 \mathrm{pm}$, which meant that the majority of people spent their days outside. With stay-at-home rules in place, the routine was reversed: residents were supposed to stay inside as much as possible. The temporary Hostel thus became a quasi-home in which to stay. From encouraging people to spend up to ten hours per day outside, Hostel staff now had to make it as easy as possible to stay in.

First, residents were allowed to remain in their rooms as long as they wanted. Second, at least partly as a result of residents' campaigning, the TV in the lounge was permitted to stay on all day long. More recently, thanks to a private donation, all residents were given tablets on which to watch television in their rooms and wifi bandwidth was increased to deal with the heavier traffic. The Hostel's manager, Paul, was happy that people mostly stayed inside and spent a lot of time in their rooms, minimizing the danger of infecting each other. Collaboration worked out in situations like this, where the solution was more or less mutually agreeable. 
When it came to mundane rules around using the lounge or watching television, though, a question surfaced again and again: how could the clock be turned back? What would happen once the pandemic ended? Paul's answer was very clear: everything would go back to normal, to stricter rules. For now, however, managing the boredom of residents while giving them a place to "stay at home" was a matter of support as well as care. Letting residents sit and watch TV was a small adjustment, but it contributed to the larger goal of keeping everyone-both inside and outside of the Hostel-safe.

\section{Supporting Addiction}

Testing has been a central part of care activities during the COVID-19 pandemic. In the Hostel, however, it was drug testing that played a particularly important role. Neil, one of the support workers usually focused on helping people with their substance use issues, told me in an interview that since the pandemic began:

I have seen two individuals that have come back to their addiction, partly due to not being able to do the drug testing. I have not been able to do them for the first weeks, but now I have given a demonstration [of how to conduct a drug test] to [frontline] staff. So they have restarted.

Even for Neil, it was not immediately apparent how important these tests were for helping people stay clean. Routines have been upended during the pandemic. Residents are bored. These facts can fuel mental health problems and spark relapses of substance use, especially as access to benefits, including money, have in some cases paradoxically increased. Neil observed this situation with one of the residents he works with:

One of my residents had a DWP [Department of Work and Pensions] back payment. He got a lump sum of money coming in and we saw the drug use went up. He started testing again last Friday, so we're confident . . . let's get him back on track.

Neil is realistic with the people he supports. Having gone through a period of intense substance use himself, he sees his role as a staff member in terms of working with residents to figure out a path forward together. Addiction is a complex problem, and many different events and contexts can trigger it. For Neil, relapsing is part of this path and supporting residents-particularly when they encounter additional triggersis as crucial as more specific kinds of care labor like mental health or addiction therapy. 
Alcohol, on the other hand, is a substance for which rules were adjusted more easily. Its consumption is another area where Hostel staff have made concessions in order to better support their residents. Before COVID-19 hit, no alcohol was allowed in the building. Dana, a long-term volunteer, explained: "Staff don't focus on [addiction issues] as long as it isn't happening on site. So I think a lot of staff might think, well, as long as the residents don't break rules or as long as they don't see it, it is not anything they need to care about." When stay-at-home measures went into effect, however, staff abandoned this rule. "Yes, the drinking is easier," Ben explains, "they are allowed to drink downstairs now." When it comes to substance use, not enforcing the rules can itself be seen as an act of support, particularly when care cannot be provided as usual.

\section{Forced to Care (with Evictions?)}

Staff at the Hostel do not usually provide care, and in fact are not legally allowed to do so. But their focus on support, on helping residents manage their day-to-day lives and connecting them to specialized care services, is no less essential during the pandemic.

As I have shown, this distinction is blurry to begin with and blurrier still in the context of stay-at-home. In the Hostel, where "home" is an indistinct concept, support takes many forms: providing a place to stay while also adhering to physical distancing; managing strong substance use habits through testing and other policy adjustments; declining to enforce certain rules too rigidly. Even so, serious and frequent violations had to be dealt with, and residents have been evicted.

Yet evictions can also be seen as one way of providing essential support in the absence of usual networks of care. In order to keep the majority of residents and staff safe, those who were not able to adhere to the rules-particularly the most important rules concerning stay-at-home-have been asked to leave. In order to provide support to the majority, Hostel staff were forced to exclude those most in need of urgent or specialized care. Hence, uncomfortably, evictions can be understood as a form of support and of care, in that the health of the majority was understood to be at stake.

Only recently has the situation changed so that staff are able to focus on support, on helping people to move on again. The Hostel has calmed down as the network of care services has slowly started to reopen, with stay-at-home orders relaxing. As Paul explained to me:

[These kinds of care services,] it was sort of paused when the emergency started; it was all about keeping everyone safe. We have started to bring back those things. We have weekly case reviews again-we go through all the people in the 
assessment centers, going through them and talking about what the needs areand if the support worker needs help. We are looking at where we can move people on to.

With care providers accessible again, the Hostel is able to focus on its central mission as a place of support for homeless people. Essential care is provided by specialists again.

Support and care became confused on the frontline, and that confusion has consequences for what essential labor entails. Hostel staff had to come to grips with the fact that, in the context of risks to health and well-being presented by the pandemic, providing support was automatically a matter of urgent care. At the same time, their work came to involve negotiations about how and when to enforce which rules. Like other frontline workers, staff at the Hostel were at times forced to acknowledge the limitations of their capacity to provide care. They also had to make incredibly difficult and painful decisions about their residents' health, well-being, and very lives.

For homeless people (and for other social groups such as the elderly) the work performed in settings like the Hostel is essential in both its support and care functions. Separating these systematically can expose both workers and residents to particular forms of vulnerability, as this pandemic has vividly demonstrated. What I have presented here helps, I believe, to build a case for thinking about essential care and support work more holistically again.

\section{Author Bio}

Johannes Lenhard is Center Coordinator at the Max Planck Center, Cambridge for the Study of Ethics, the Economy, and Social Change. His PhD research focused on survival practices of homeless people in London and Paris. More recently, he has started new research projects on the impact of COVID-19 on homeless people and support services, as well as the ethics of venture capital investors in Europe and the United States. 


\section{Preview Image}

Courtesy of Gilbert Mercier.

\section{Notes}

1. To protect the anonymity of staff, volunteers and residents, the names of the institution(s) and of all participants have been changed and certain details adjusted. Quoted speech is not verbatim, as it was reconstructed from retrospective fieldnotes rather than recordings.

2. Likewise, in the Ministry of Housing's "Homelessness Code of Guidance" from 2018, the focus for service providers is on support and not on care. Paul also distinguished between institutions like his that did not need to be registered with the Care Quality_ Commission and facilities like care homes, hospitals, and mental health providers, which did. 